\title{
The Editor, the Journal, the Project
}

\author{
Russell A. Berman
}

To write about the history of Telos today remains a challenge because the memory of its founder and, for decades, its moving spirit, Paul Piccone, is still so strong. Is it the gravitational pull of the recollection? In that case, we are confronted with the simple problem of proximity: it may still be too soon to write a history of the origins of the project; we need a greater historical distance to gain perspective and objectivity. Yet perhaps it is not the force of memory but the magnetic pull of the personality: Piccone defined the journal and its evolving project, and he left his mark in ways more effective and more durable than did the editors of many of the competing or comparable journals that took shape in the wake of 1968. Surely both hypotheses hold, and, with time, an intellectual historical account of Telos might become possible that would pay attention solely to the ideas and not the personalities. Whether that will be a gain remains to be seen, a history of ideas without subjects. The doubt about such an undertaking points to the weakness of intellectual history as such, when the people who have the ideas fade into the background, no matter how unavoidably. For now however, Piccone's centrality remains unmistakeable; he still casts a long shadow. Indeed for this writer, even referring to him in by his last name conveys a sense of pseudo-objectivity and unwanted distance, although the first name would redefine this text as simple reminiscence or eulogy. As the journal outlives its founder, it is jarring to encounter new associates and to realize that they never met Paul.

The problem is worthy of some theorization. If thoughts matter, what about the thinkers? And do the lives of the thinkers define and limit the significance of the ideas? The bad version of this connection instrumentalizes the life, or more typically, particular snippets, in order to denounce the ideas: the thinker lived in such and such a way, did this or that, and made certain decisions, and the epigonic historian wields these factoids as denunciations of the ideas. This hermeneutics of suspicion, the programmatic debunking of thought, depends on an epistemology that asserts the priority of context and material conditions over any act of the mind: reductionism (as critics of Marxism used to say ) or mechanical materialism (in the terminology of the dissident philosophical Marxists). It is in any case the real anti-intellectualism because it systematically evades ideas by invoking conditions: context is the pretext to suppress the text. The life of the man becomes exhibit A against ideas: but what would the ideas be without the life?

After all, the individual is surely not only a product of the context; the individual who, through acts of the mind as well as physical perseverance, establishes objective culture, does not only reflect the givenness of the world, even if that work of culture -here: the accomplishment of founding and fostering the journal—bears the mark of its founding author. How much of his life informed and continues to pervade the legacy? The interpretive challenge, which cannot be met here, will be for a future historian to tease out the difference between the imprint of the founder, an editorial version of authorial intent, and the relative autonomy or indeterminacy of the journal itself. Telos was unthinkable without Piccone, but Telos was not only Piccone; he set in motion a rich and dynamic cultural community, in which he played a vocal part, in a larger-than-life way, but it was always only a part, never the whole, as the intellectual contents cascaded through decades, surpassing control. The point is not only that the journal continues after Piccone's death, but that during his lifetime as well, for all of his magnetism and zeal, the journal also had a life of its own.

Recognizing the challenge to think through the relationship between Telos and Piccone is in part about a process of institutional maturation beyond the will of the charismatic founder. However this ambition was inscribed from the start, within the legacy of Piccone, the phenomenologist. To be sure, the critic of orthodox Marxist reflection theory, the philosopher and social theoretician, for whom quantitative social science was anathema, was certainly 
no idealist, no formal logician. Yet his program involved the repeated and repeatedly refined positing of a dynamic relationship between the mobile and unstable world of ideas, on the one hand, and the preconceptual experience of the life-world, on the other. Modern sciences (Marxism-Leninism included) reduce ideas to the world; an abstract idealism ignores lived experience. A radical phenomenology as the basis for a critique of modernity maintains the tension: hence the project of Telos as well as the challenge for a historian of the enterprise.

Piccone lived the life of an intellectual editor in what seems like a distant age. The context for intellectual life changed radically during the last third of the twentieth century, and this transition too will become an indispensable part of a history of the journal as part of a to-be-written account of the structural transformation of the public sphere since 1968. Even then, however, it was clear that the culture of public intellectuals was migrating out of the public square and into the universities, and this shift took place long before the term "public intellectual" took on the connotation of media celebrity that it acquired around 1990. Russell Jacoby has chronicled part of this transformation. That Telos moved to New York pretty much after the end of the age of New York intellectuals has its own irony, but one has to pay attention to the specific location. Piccone's New York relocation was not into a world of the intellectual elite-the nostalgic image of bohemian Greenwich village for earlier generations of American thinkers - but to the then very scruffy lower East Side in a brick building behind a convent and across the street from a public school, very much in a neighborhood devastated by the decline of urban life. Of course, in Manhattan, the Telos office could be a meeting place for many, including a constant stream of visitors from abroad: but in New York, Piccone was not an old school New York intellectual, because that very type of intellectual had in effect disappeared. Indeed reflection on that disappearance of an older intellectual world as part of the transformation of post-Great Society, post-1968 American culture represented an underlying concern for the journal during the seventies and eighties, if never so explicity as for the mainstream neo-conservatives.

In fact, many aspects of Piccone's intellectual life-world could be described in terms of anachronism, especially from today's vantage point. Most of his work took place before the full impact of internet and the opportunities for intellectual networks that the new technologies have brought: Telos still assumed a capitalism that was not very fast. Similarly, he worked in a world in which many more independent bookstores carried hard copy journals for a readership more attuned to ideas than is currently the case. Since then, the conditions of possibility of the life of the mind have changed, radically, no doubt. Times change. That said, it is important to recognize a few aspects of Piccone's intellectual practice that, far from anachronistic, were remarkably foresighted and provided the journal with some key advantages, without imposing any inflexible agenda: the network of participants, the positioning vis-à-vis the universities, and a programmatic intellectual risk-taking.

From the start, Piccone successfully built communities of Telos supporters: readers, authors, students, often in multiple locations. This was network construction before the internet. Especially during the 1970s, "Telos groups" thrived on several university campuses in the US and Canada, and Piccone himself maintained connections to academics and intellectuals in North America and Europe. This ability to mobilize participants is all the more remarkable since there was no remuneration, unlike with commercial publications or those journals that became baubles of university presses. If there was reward, it was in the sense of participation and the generosity of Piccone's fabled hospitality. To be sure, many of the editorial board members and others in the circles around the journal were affiliated with North American universities but_ and this is a second element of the Telos strategy-Piccone kept established academic life at arm's length. Unlike the other so-called radical journals that found perches within the stale neo-Marxism of the universities and their presses, Telos never aspired to become a ward of a university, surviving instead on subscription income, the dedication of the participants and the self-exploitation of the editor. It could participate in debates unfolding within academia, without being fully of the established academic world; in this sense, it resembled public journals, rather than narrowly professional ones, a legacy of a broader vision of intellectual life. Another historiography will be able to ask how professional academic life, especially in the humanities, probably always benefits from extra-academic discourse, a life-world for ideas that exists outside the ivory tower. This is the gray zone that Telos could inhabit. (It is similar to the ambiguous terrain that lies between professional political science and the political public sphere, or between literary scholarship and creative writing in the publishing world.) The point is not simply that this liminal status can be particularly productive, which it certainly has been. There is something much larger at stake: against the thesis that an older intellectual life of public intellectuals had given way to a migration of intellectuals into the ominous embrace of the university, we can now-especially amidst the economic crisis - recognize a counter-tendency, the reduction of intellectual life within the universities, the problem that currently takes the shape in pessimistic accounts of the future of the humanities. Perhaps universities will not 
turn out to be as hospitable to the life of the mind as was once imagined. If, during the 1980s and the heyday of deconstruction and the culture wars, it could seem that the humanities could live a vibrant life within academic structures, in retrospect, and thinking about that era, we may have just been witnessing the gradual subversion and self-destruction of the humanities, whose place in the universities is by no means secure. Back then "theory" announced it as the post-humanist agenda, which the economic crisis may yet carry out. Telos has good reason to establish itself as an independent entity and to explore the life of the mind outside of the professionalized disciplines: if not with greater security, then at least a clearer insecurity.

On the outside, the journal could take risks, not constrained by the pieties and caution that, beneath a veneer of liberalism, all too often characterize the sanctioned intellectuality of the universities. Over the course of its career, Telos has played a contrarian role in intellectual life, taking non-standard and indeed unpopular positions, but therefore wielding considerable influence on the larger discussion, like a third party in American politics. In general, these risks have proven to have been more than worthwhile. If today it is difficult to imagine a topic of intellectual history less controversial than Critical Theory and the Frankfurt School, it is crucial to remember how much the anti-Communism and critical Marxism of Adorno, above all, represented an affront to New Left sensibilities throughout the 1970s. While the journal's engagement with the Frankfurt School was rarely hagiographical and quickly involved a critique of vestigial Hegelianism and Marxism even in the most Adornian of texts, interlocutors on the left characteristically denounced the journal, either for engaging with Critical Theory at all or for drawing anti-Communist conclusions. Any credible intellectual history of the era should not omit how much polite sensibility in the era was built around accepting détente and the Soviet presence in Eastern Europe: solidarity with dissidents was rare indeed, and the journal faced denunciations from the left that preferred to suppress any knowledge of the Soviet occupation. The historical answer to that collaboration was 1989, a transformation that the left has yet to internalize-except one fears that that moment may itself have already passed, with the reassertion of Russian hegemonic interests in Eastern Europe, the decline of free markets and the push back on rights. These are the multiple layers around the engagement with Adorno in the 1970s: left common sense was adamantly hostile to accounts that could have anti-Communist character or challenge Soviet rule. Telos solidarity with Eastern European dissidents was right then; and the time may soon come when that solidarity will be necessary again, given Russian aspirations, a weak-willed old Europe, and Yaltan proclivities among American Democrats.

Another intellectual risk involved the engagement with the writings of Carl Schmitt. As different as he is from Adorno, their reception histories in the academic world are uncannily similar. Like Adorno, Schmitt appeared on the horizon, initially, as a hopeless pariah, and Telos' interest in him was nothing less than a scandal. Our interests had similarly scandalized the left, as discussed above (and it still does, in some circles), just as it seems incomprehensible to professional philosophy. Yet by now Adorno is mainstream, published by major university presses, and correspondingly anodyne, and Schmitt too has moved to the center of many scholarly discussions. If Agamben and Zizek represent the center of some current academic debates, surely reading Schmitt has become indispensable. Telos has published the key volumes.

A third risk: the turn toward a discussion of religion and the strategic alliance with the "Radical Orthodoxy" group in England. When we first began to raise the question of religion, as part of a prior discussion of tradition, we faced similar astonishment and disbelief. Was this not more evidence of a turn to the right? How could one pay attention to religion, except as pathology? Breaking another left-liberal taboo, Telos began a discussion of religion, and since the 1990s it has become absolutely clear how much religious movements have entered the public sphere, and how pointless it is to try to discuss political developments without reference to religion. Religion, moreover, was recast as heir to Critical Theory's capacity to articulate critiques of modernity through objectification of transcendence, especially in the problem of liturgy.

This is not the place to elaborate on the "liturgical critique of modernity" at length: there are plenty of extended treatments in the journal itself. The point here however is that all three moves that have defined Telos and scandalized the guardians of old myths-the approach to Adorno, the engagement of Schmitt, and the attention to religion-were, in retrospect, undeniably bold shifts into registers of thought inimical to currently held belief structures and which elicited resistance as passionated as anything in academic life. Intellectual risk-taking outside the protected sphere of universities - perhaps precisely because we were outside of that sometimes stifling protection—contributed to the profiling of the journal as an agile guerilla, a partisan in the world of thought, staking out territory from which we could nimbly attack the edifices of established opinion.

A similar complexity, in which adamant intellectuality pushes against academic convention, pertains to Piccone 
in another important dimension, which some of the current editors were lucky enough to encounter: his role as a teacher. The hypothesis that the journal stood just outside the established academic world rests on the claim that that academic world faced its own self-imposed limitations and relied on an outside force, like Telos to discover new ideas. Its negativity toward the academy contributed to the ability of the academy to thrive, despite itself. As teacher, Piccone demonstrated a classroom enthusiasm and an engagement with students, which, enormously productive for students, largely ran counter to the expected behavior, the proper professorial habitus, in the research university of the 1970s and 1980s. Scholarship as vocation demanded the extirpation of charisma and the priority of objective and distanced method. Piccone's personality and its conceptual apparatus displayed diametrically opposed orientations: community, values, participation. Eulogistic accounts sometimes attribute all this to his own idiosyncratic character, and this is certainly not untrue. But there is much more at stake than idiosyncracy, or rather, the objectivity of idiosyncracy involves its antagonism to dysfunctional convetions. Piccone's manner as teacher inherited an older intellectuality, the genealogy of which points back to educational agenda that predate the reified research university, but which also anticipates the current deep-seated transformation in the understanding of pedagogy in higher education. His classroom demeanor was not about systematic coverage of material; it focused instead on his distinct success at animating the students' learning process through his own contagious enthusiasm, the challenge of Socratic method, and the perpetual involvement of students in project-based learning: this was the tried-and-true recruitment mechanism for the journal. These projects should be understood however less as a strategy to recruit support for Telos (which they also were) but as an outstandingly successful pedagogical strategy to enhance student learning. Piccone, one can say with understatement, decentered the existing paradigm of the university professor, and if the university therefore turned its back on him, the more important point involves his far-sighted and anticipatory teaching methods. At stake then in the lessons of the teacher Piccone is the very contemporary question of the role of the humanities faculty in the research university, now at a moment in time at which the value-added for students has to be rethought radically. Piccone was, if anything, three decades ahead of his time in the reinvention of the role of the professor. Far from a vestige of a distant past, before the internet, from from an outdated anachronism, he stands as a harbinger of things to come. Much of the historical labor of Telos in the early years involved working through a still very hegemonic Marxism and dismantling its categories one by one: the scientism, the laws of development, the narrative of history, the determinism. If there is one element of that tradition that survived, transformed, Piccone embodied it as the pending revolution in teaching, on which any prospects for the survival of the humanities depend.

So while one can certainly tell the story of Telos in terms of legacy, an inheritance from a past, and in terms of the distance of that past, another era before the new technologies, this alternative account recasts the journal as the canary in the coal mine of the university. The crucial point in the narrative of Telos was not the founding editor's distinctiveness or the maverick positions or the small scale of the operation: the point, rather, was the development of new strategies of intellectual life and new critical potentials, somewhat ironically through European intellectual traditions, in order-this is clear in retrospect-to trace new paths in the changing American context of late modernity. New forms of intellectual networks, new terrains of idea-formation, new modalities of teacher-student relations: Telos has contributed to an elaboration of the road-map for radical changes in the university that the establishment, still committed to the orthodoxies of the research university and Weberian dogma, tries to maintain at the risk of losing it all. The humanities could burgeon in the mid-twentieth-century university due to an anomalous constellation of factors - the demography of the university, the shift to an information economy, and some inherited cultural traditionalism. All of this came under pressure in the last decades of the twentieth-century: there is no longer a generally credible argument to make for any single set of cultural material, which means that no canon any longer has persuasive force. At the same time, the rise of technocratic and preprofessional cultural demands only places greater pressure on the humanities, while minimizing the importance of the very core of humanistic learning, the possibility of transcendence, and the capacity of the human mind to escape contextual limitations. While this transcendent dimension represents a crucial necessity for any culture to thrive, we should not assume sanguinely that we cannot lose it. Critical Theory, in its various permutations, always feared this loss of creativity, the naturalistic reduction of humanity to mere fact. Resisting that diminishment has always been the goal, the telos, for the journal. There is a time for nostalgia, and a time to put it aside. The cultural criticism developed over decades through Telos provides deep resources with which to face the crisis of the humanities today. 